\title{
Tools to improve inclusion in multistakeholder forums (MSFs)
}

Kristen Evans and Iliana Monterroso

\section{Key messages}

- Organizers and designers of multistakeholder forums (MSFs) are increasingly seeing the inclusion of women and Indigenous Peoples as both a responsibility and duty. However, in a global survey, practitioners also informed us that they needed tools to help them apply a rights-based framework to their work and improve inclusion in practice.

- Responding to this need, we used our findings to develop a theory of change and two tools to help practitioners focus their inclusion efforts, providing step-by-step instructions on how to apply these tools in an MSF setting, as well as examples.

- Getting it right is the result - a practical guide that draws on lessons learned from the literature and practitioners around the world, to help organizers and designers of MSFs unpack and operationalize the inclusion of women and Indigenous Peoples.

- This infobrief provides an overview of the process behind creating the guide, its key features, and recommendations for next steps.

- Possible areas of future research include lessons learned and best practices from the application and testing of the guide, as well as understanding the success factors and constraints specific to other under-represented groups.

\section{Background}

MSFs are being promoted in natural resource management, climate policy and local forest use to support consultation, information sharing, policymaking and decision making. We define MSFs as a "purposefully organized interactive process that brings together a range of stakeholders to participate in dialogue and/ or decision making and/or implementation of actions seeking to address a problem they hold in common or to achieve a goal for their common benefit" (Sarmiento Barletti et al. 2020b, 2).

However, the lack of inclusion of women, Indigenous Peoples and other groups, such as Afro-descendants, lower-caste groups, LGBTI, the poor, the elderly, young people, people with disabilities and pastoralists, remains a crucial problem. Barriers for women include lack of mobility, being overburdened by household duties and lack of childcare. They also include issues of capacity and confidence, highlighting the need to strengthen women's capacities in leadership, negotiation and organizational skills. In many cases, social norms prohibit women from speaking in front of men. Barriers for Indigenous Peoples also include lack of resources to ensure mobility, as well as structures that privilege nonIndigenous knowledge systems, and decision-making processes that benefit the majority. While progress has been made, the realist synthesis review on MSFs by Sarmiento Barletti et al. (2020b) identified key issues with existing efforts to improve inclusion in MSFs; for instance, framing simple attendance as inclusion may actually exacerbate inequalities. Despite this, opportunities do exist to help MSFs elevate the voices of underrepresented groups.

We defined inclusion as "the process of improving the terms of participation in society, particularly for people who are disadvantaged, through enhancing 
opportunities, access to resources, voice and respect for rights" (UN 2016, 17). In the context of MSFs, inclusion means ensuring that no institutional frameworks, social norms or forms of identity unfairly influence decisionmaking processes, nor exclude people from engaging actively and participating effectively in any decision that affects them.

\section{Creating the guide}

Our goal was to better understand the problems of inclusion as well as their solutions, and then use our findings to create a practical guide to operationalize inclusion. We sought to problematize how we usually think of participation, and bring to the fore issues of representation and power differences. We also looked to introduce a more nuanced understanding of the barriers to engagement. The result of this was Getting it right: A guide to improve inclusion in MSFs (Evans et al. 2021), which is oriented towards the planners and organizers of MSFs at the national, subnational and local levels. This guide builds on How are we doing? A tool to reflect on the process, progress and priorities of your multistakeholder forum (Sarmiento Barletti et al. 2020a). Below, we present an overview of the process behind creating the guide, its key features, and recommendations for next steps.
To prepare the guide, we reviewed the literature and surveyed experts around the globe to identify best practices and lessons learned in how to approach inclusion (see Figure 1). The end result draws on these findings to explain how to operationalize the inclusion of women, Indigenous Peoples and other underrepresented groups in multistakeholder forums (MSFs) using a rights-based approach. The guide includes a theory of change and two tools to help organizers and planners of MSFs create a roadmap for change by facilitating the development of strategies and mechanisms to assess whether goals are in line with expectations.

We chose to focus on women and Indigenous Peoples for several reasons. First, looking at both groups provides two different lenses for understanding the problems of inclusion. Specifically, understanding the constraints and success factors for women focuses on dynamics at the individual, household and intra-community levels, while understanding the issues surrounding Indigenous Peoples provides insights into the treatment of a specific group. Looking at two identity groups provides a way to see differences and similarities, as well as better understand how and under which circumstances these two dimensions of social differentiation intersect.

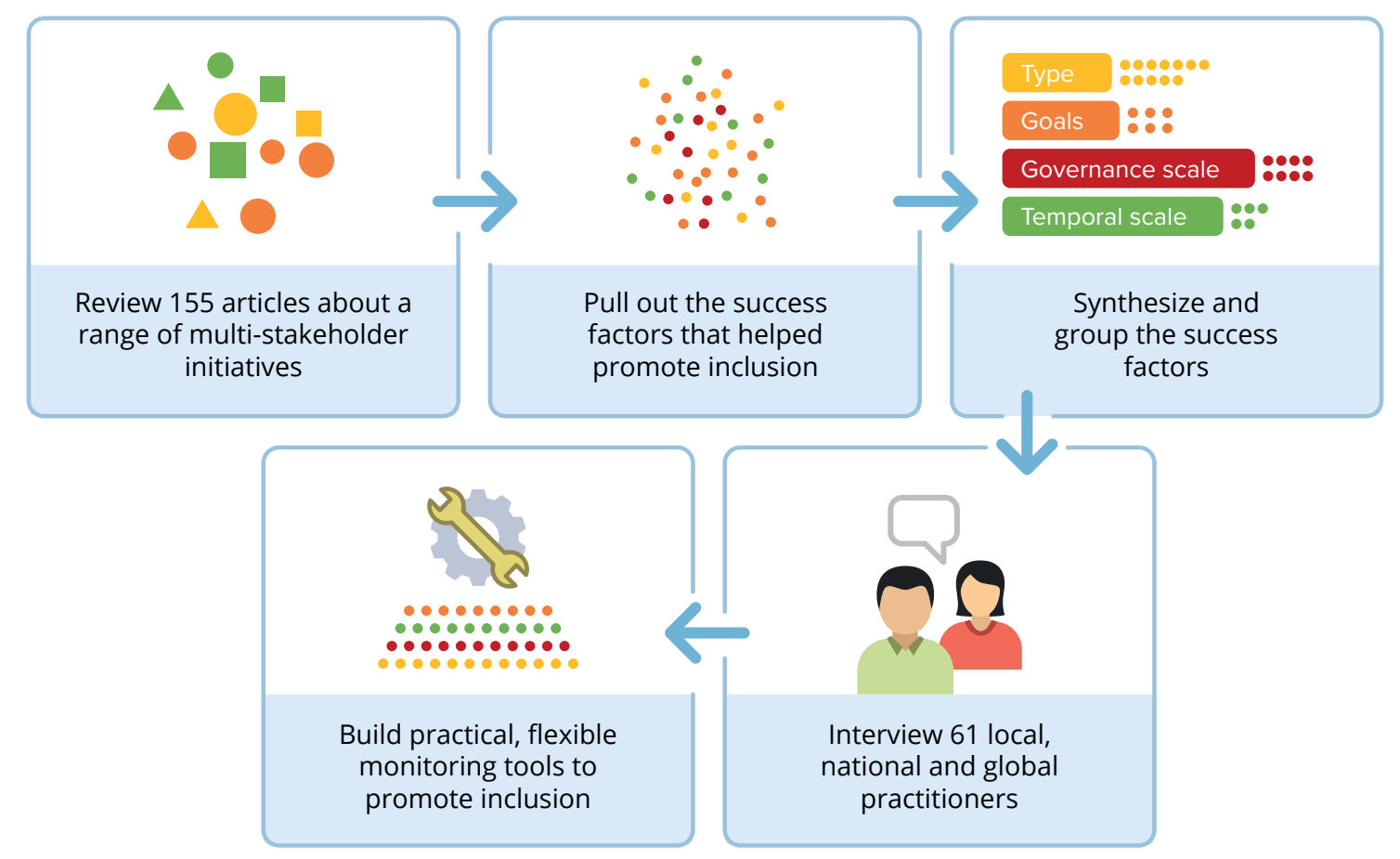

Figure 1. Our approach for creating 'Getting it right: A guide to improve inclusion in MSFs 
We also explored the intersectionality of the two, i.e., Indigenous women, to better understand how group norms and individual constraints can affect inclusion. We believe that the lessons learned can be applied to other under-represented groups.

We chose a human rights-based approach because it reframes stakeholders as rights-holders, making inclusion a central responsibility of MSFs. We are also responding to needs expressed by the practitioners we interviewed, who informed us that they are looking for more tools to help them apply a rights-based framework to their work. A rights-based approach shifts development from an act of charity to an obligation, or duty, to rights-holders. In the context of an MSF, a rights-based approach acknowledges that engagement of these groups should not be a token effort, but actually a goal in itself, in MSF structures.

\section{The process}

Our team included researchers in Asia, Africa, Latin America and North America; work was conducted in different languages and with people who had knowledge of the regional contexts. We also connected with global stakeholders, defined as development, research or finance institutions working across regions. We conducted a literature review of 155 articles that discussed multistakeholder initiatives in three natural resource management approaches: protected areas, REDD+ and community forest management. We identified success factors and constraints to inclusion.

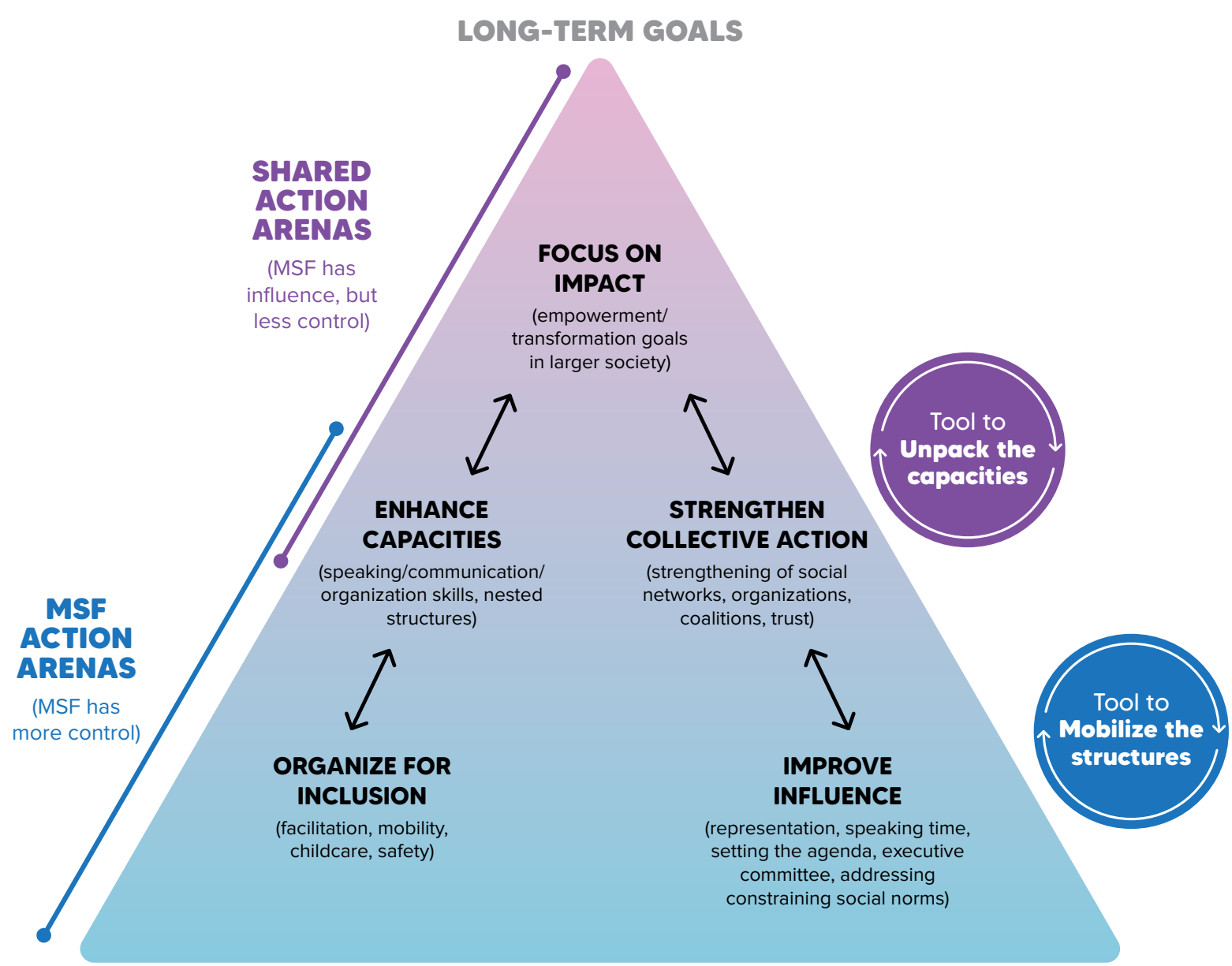

SHORT-TERM GOALS

Figure 2. The theory of change (TOC) shows where MSFs can control and influence change to reach empowerment goals 
Success factors include those enabling conditions, characteristics, activities, attitudes or events that promote the inclusion of women and other underrepresented people and their ideas, values, knowledge and priorities in MSFs in a meaningful way, including decision-making processes and activities. We interviewed 61 local, national and global experts to update and augment our findings with the perspectives of on-the-ground practitioners.

Based on our findings, we developed a theory of change (TOC) that identified action arenas where MSFs can have an impact. Theory-based assessment approaches are often used in research-for-development in order to identify the steps or impact pathways in the change process (Belcher et al. 2017). Briefly put, a TOC is an approach for identifying goals, and strategies for reaching those goals. We synthesized and grouped success factors into five action arenas which align with the TOC (see Figure 2). Action arenas refer to both individuals and the social spaces where they interact, exchange information, solve problems and even engage in constructive conflict (Ostrom 2011). Our proposed action arenas reflect short and long-term inclusion goals, as well as the spectrum of influence that the MSF has in achieving the goals.

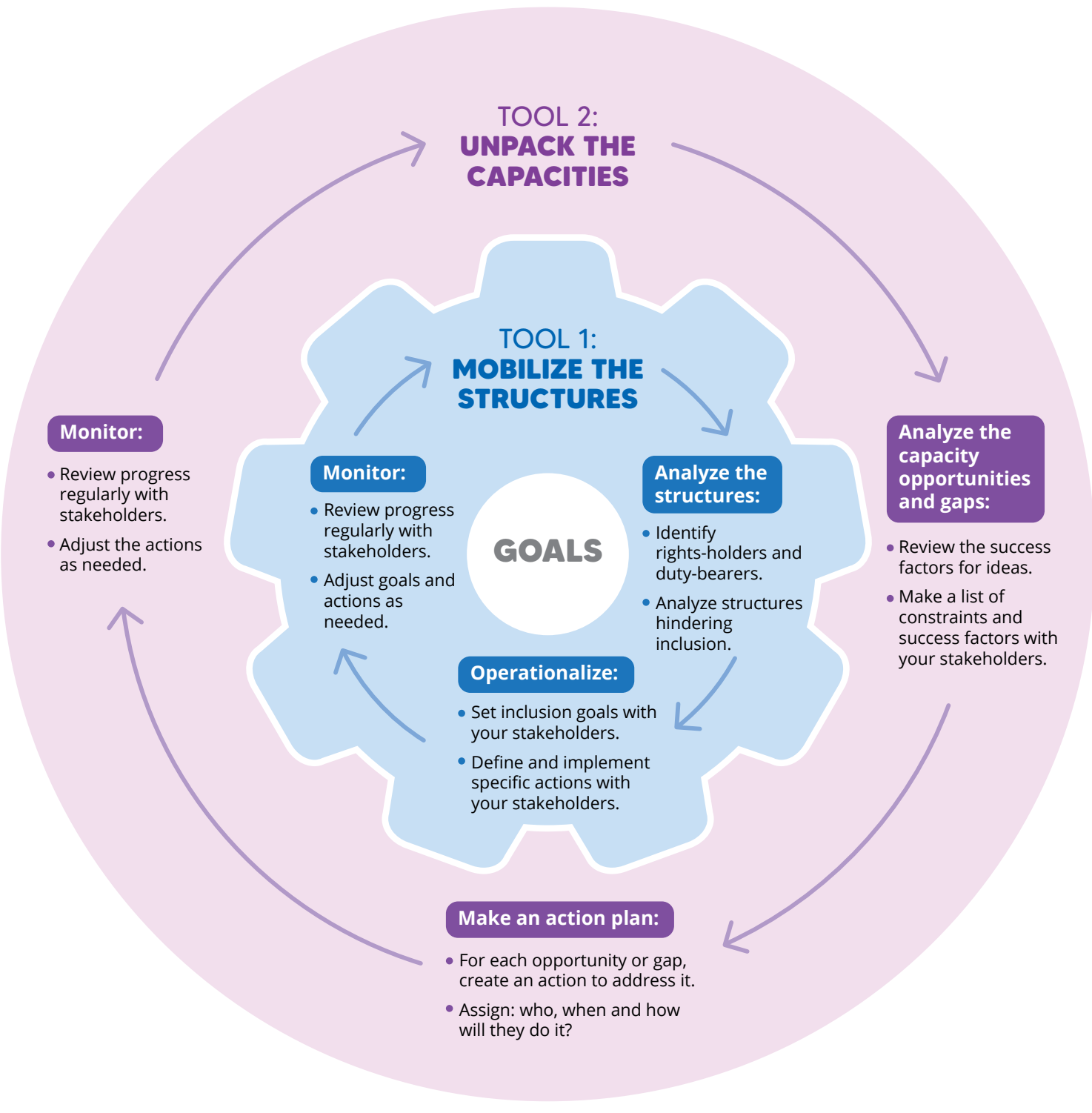

Figure 3. Two tools to operationalize inclusion 


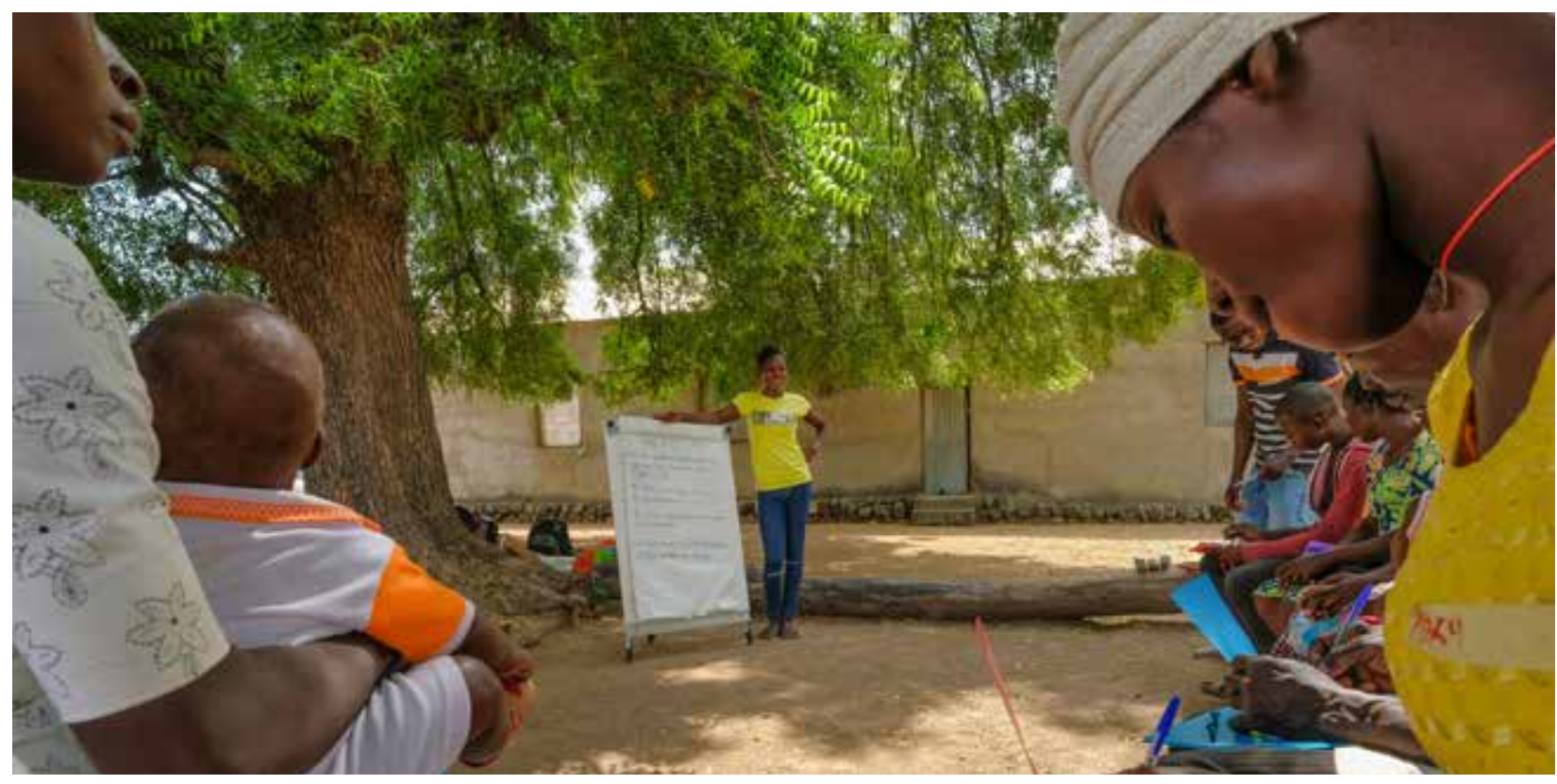

The Mobilize the structures tool aims to support MSFs in setting gender and social inclusion goals.

Photo: A mapping workshop in Kassena-Nankana West District in the Upper East region, Ghana, by Axel Fassio/CIFOR.

The TOC recognizes that the goal of inclusion occurs in an ecosystem, requiring coordination with other processes, partners and stakeholders. Some barriers and challenges remain within the scope of the MSF, but others go beyond the specific goals of these spaces, and can only be addressed through longer-term collaborations.

In order to help MSFs reach their empowerment goals, we developed two tools (Figure 3) that provide specific mechanisms to effect change in the action arenas. The tools are designed to be used by the organizers and implementers of an MSF in collaboration with key stakeholders, particularly those from under-represented groups. Mobilize the structures examines the institutional arrangements and structures that can promote or constrain inclusion in MSFs, and suggests mechanisms for strategic goal-setting as well as monitoring actions to catalyze change. Unpack the capacities uses the success factors as a framework for analyzing opportunities to enhance capacities and identifying existing gaps in an MSF. The tools can be used in any order or applied in parallel, ideally in an progressive, iterative approach to create opportunities for improvement and group learning. The guide provides step-by-step instructions on how to apply these tools in an MSF setting, as well as examples.

\section{Making it work}

In addition to developing the TOC and practical tools, the guide presents key lessons learned from the practitioners, practical advice and examples. Based on our findings, one successful approach is creating nested structures in the MSF (working groups, subgroups) to create more opportunities for leadership and participation; this can also ensure the MSF is more geographically accessible for participants. There are also several key points in the process to improve inclusion: when the agenda is defined, and when decisions are made about who serves on the executive committee. Practitioners also recommend rethinking how the format of an MSF can give voice to the underrepresented, since the current format is usually defined by those in power. It is also important to ensure that the MSF has a legitimate strategy and weight for providing input into policy change, and is not simply used as a consultative process to benefit powerholders, with no specific end or purpose that serves participants. Finally, inclusion is a process that takes time and continuous effort, often over many years.

Possible areas of future research include lessons learned and best practices from the application and testing of the guide, and understanding the success factors and constraints specific to other under-represented groups. 


\section{Acknowledgements}

This work was undertaken as part of the CGIAR Research Program on Policies, Institutions and Markets (PIM), led by the International Food Policy Research Institute (IFPRI), and the CGIAR Research Program on Forests, Trees and Agroforestry (FTA), led by CIFOR. We would also like to thank Nathalie Elwell and Chloe Ginsburg for their helpful reviews and comments. This work has been carried out under the CGIAR GENDER Platform. This publication has gone through CIFOR's standard peer review procedure. We are grateful to Rights and Resources Initiative for supporting this research, and to their staff, for their deep engagement at all phases of the study.

\section{References}

Belcher B, Suryadarma D and Halimanjaya A. 2017. Evaluating policy-relevant research: Lessons from a series of theory-based outcomes assessments. Palgrave Communications 3:1-16.
Evans K, Monterroso I, Bwire D, Liswanti N, Tamara A, Mariño H, Sarmiento Barletti JP, Larson AM. 2021. Getting it right: A guide to improve inclusion in multistakeholder forums. Bogor, Indonesia: CIFOR.

Ostrom E. 2011. Background on the Institutional Analysis and Development Framework. Policy Studies Journal 39:7-27. https://doi.org/10.1111/j.15410072.2010.00394.x

Sarmiento Barletti JP, Larson AM, Cisneros N, Heise N, Liswanti N, Mariño H and Tamara A. 2020a. How are we doing? A tool to reflect on the process, progress and priorities of your multistakeholder forum.

Bogor, Indonesia: CIFOR. https://doi.org/10.17528/ cifor/007796

Sarmiento Barletti JP, Larson AM, Hewlett C and Delgado D. 2020b. Designing for engagement: A Realist Synthesis Review of how context affects the outcomes of multistakeholder forums on land use and/or landuse change. World Development 127:104753.

UN (United Nations). 2016. Leaving no one behind: The imperative of inclusive development. Report on the World Social Situation. New York: UN.
GENDER

Platform
This work has been carried out under the CGIAR GENDER Platform, which is grateful for the support of CGIAR Trust Fund Contributors. www.cgiar.org/funders

\begin{tabular}{|l|l|l|}
\hline $\begin{array}{l}\text { RESEARCH } \\
\text { PROGRAM on } \\
\text { Policies, } \\
\text { Institutions, } \\
\text { and Markets } \\
\text { Led by IFPRI }\end{array}$ & $\begin{array}{l}\text { The CGIAR Research Program on Policies, Institutions, and Markets (PIM) leads action-oriented } \\
\text { research to equip decision makers with the evidence required to develop food and agricultural } \\
\text { policies that better serve the interests of poor producers and consumers, both men and women. PIM } \\
\text { combines the resources of CGIAR centers and numerous international, regional, and national partners. } \\
\text { The program is led by the International Food Policy Research Institute (IFPRI). www.pim.cgiar.org }\end{array}$ \\
\hline \begin{tabular}{l|l} 
CGESEARCH \\
PROGRAM on \\
Forests, Trees and \\
Agroforestry
\end{tabular} & $\begin{array}{l}\text { The CGIAR Research Program on Forests, Trees and Agroforestry (FTA) is the world's largest research } \\
\text { for development program to enhance the role of forests, trees and agroforestry in sustainable } \\
\text { development and food security and to address climate change. CIFOR leads FTA in partnership with } \\
\text { ICRAF, the Alliance of Bioversity International and CIAT, CATIE, CIRAD, INBAR and TBI. } \\
\text { FTA's work is supported by the CGIARTrust Fund: cgiar.org/funders/ }\end{array}$ \\
\hline
\end{tabular}

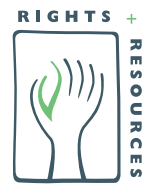
partners' capacity, and actively engaging in dialogue with all stakeholders to inform policies and practices that affect forests and people. CIFOR is a CGIAR Research Center, and leads the CGIAR Research Program on Forests, Trees and Agroforestry (FTA). Our headquarters are in Bogor, Indonesia, with offices in Nairobi, Kenya; Yaounde, Cameroon; Lima, Peru and Bonn, Germany. 